\section{A CHOLERA CENTENARY BY}

\section{MAJOR GREENWOOD, D.Sc., F.R.C.P., F.R.S.}

More than 270 years ago Sydenham predicted that the epidemic diseases which he saw would give place to others the nature of which it was impossible to foresee. He was writing some ten years after the last epidemic of plague on a grand scale in Great Britain. Just a hundred years ago our great-grandfathers, to whom plague was a distant memory, suffered the second epidemic of Asiatic cholera, which has not afflicted us since 1866 . In London the worst week was that ending September 8,1849, with 2,021 deaths ; four weeks later the total had sunk to 288 , and the epidemic rapidly declined. It killed more than 50,000 persons in England and Wales-about as many as the war in the air of our time. Now we study with a certain anxiety the much smaller figures of notified poliomyelitis; with a certain anxiety because, epidemiologically speaking, we do not know so very much more about it than our great-grandparents knew about cholera. Sydenham was a good prophet. The cholera of 1849 was the subject of three bulky reports, by the General Board of Health, by the College of Physicians, and by the General Register Office. Copies of them, even those in an epidemiological department, need to be handled cautiously in these days of soaprationing; they are apt to be very dusty. That published by the College of Physicians is the most readable because it is not very statistical and is the work of a single author, William Baly (1814-61), a physician of sufficient importance to be remembered by D.N.B., but hardly even a name to most of us.

William Baly, a student at University College and Bart's, graduated M.D. at Berlin in 1836, became physician to the Millbank Penitentiary in 1841, and F.R.C.P. in 1846 ; he was thought to be a rising man, and was appointed physician to the Queen, as understudy to Sir James Clark, in 1859. He was killed in a railway accident when 47 . His report is quite readable and strictly orthodox, as the official report of a professional body is sure to be. A reader in 1949 may say that, generally speaking, when Baly was quite sure, he was quite wrong, and when he doubted he inclined to the wrong side. That, however, is a grossly unjust way of judging an official report made by a young man a hundred years ago. We are children of our age, deserve blame if, intellectually and morally, we are behind it, but certainly none if we fail to anticipate future discoveries.

In 1849 Galenical epidemiology was well stricken in years but still vigorous; Southwood Smith (1788-1861) and John Sutherland (1808-91), two of our best practical epidemiologists, were Galenists in the sense that the epidemiological importance of tainted air, of miasma, was to them much greater than that of contagion. There was indeed then living one man, Jakob Henle (1809-85) who published in 1840 in his pathological researches a remarkable essay on miasmas and contagions (it was reprinted, in Sudhoff's series of Klassiker der Medizin, in 1910) which Baly might have read. Henle's argument was, briefly, this : that while in ancient medicine most epidemic diseases were reckoned to be miasmatic, now-viz., in 1840-only one, malaria, would be universally regarded as purely miasmatic ; three-syphilis, scabies, and hydrophobia-would be classed as purely contagious. All the others-smallpox, measles, cholera, etc.- he classified as miasmatic-contagious, but very plainly indicated his opinion that the emphasis should be on the contagious side. He then-as had Fracastorius (1483-1553) nearly 300 years before-put forward the idea of a living contagion, perhaps a minute vegetable organism, as the specific biological cause of exch disease and, more fortunate than Fracastorius, could point to a striking analogy, the epidemic disease of silkworms-muscardine-which had been proved by Bassi and Audouin, a few years before he wrote, to be due to a vegetable parasite. But Henle could not demonstrate any such contagium vivum in connexion with human epidemic diseases, excluding scabies.

Baly does not mention Henle, but he does speak of John Snow (1813-58), who had already urged that cholera was a water-borne disease, and, quite courteously but emphatically, rejected his conclusion. Probably if Baly had written four or five years later he would have taken Snow much more seriously, because'Snow's conclusive statistical proof that, as we should now say, mortality from cholera and the drinking of polluted water were highly correlated was based upon the epidemic of 1854 . Baly, although no statistician himself, had a considerable respect for statisticians and whole-heartedly accepted Farr's demonstration that low altitude and high mortality from cholera were highly correlated. Indeed, it was the basis of his general argument, which was this. The cholera poison is not a vapour or miasma but a solid " something" usually conveyed by air currents. If this "something" reaches a low-lying district, harbouring a poverty-stricken, overcrowded population where filth accumulates, then cholera will arise ; low-lying, damp, foggy sites were sites of election. He contrasts the erratic lines of travel and the persistence of cholera with the universality of the great influenza of $1847-8$, which no doubt he considered a typical purely miasmatic disease. He was fair-minded; he admitted the possibility-indeed, the probability-that the cholera poison might be introduced by other means, that the disease might be contagious. $\mathrm{He}$ is, however, almost as reluctant to accept contagion as a vera causa as was Henle to admit miasma as a reality.

What must strike a modern reader, and might have struck a contemporary, as Baly's weakest dialectic is in his discussion of how the Asiatic cholera reached Europe and America. He agrees that the cholera could spread against the wind, in the teeth of the Monsoon; he agrees that it followed the line of human intercourse, that it entered at the ports, moved up waterways, and so on. Surely it was easier to suppose that the continuance of cholera in a ship was due to the persistence and multiplication of a contagium vivum in the bodies of the patients than to try to exclude contagion from one's argument? That once admitted, conversion to Henle's standpoint would follow. But it is easy to be superior; we know much more about cholera than even Henle and Snow, but no epidemiologist would be bold enough to explain why the epidemic of 1866 was our last.

Baly's section on preventive measures is very short and is no more than a colourless abbreviation of what Southwood Smith and Edwin Chadwick had recommended much more forcibly for the mitigation of all epidemic diseases. The devil's advocate may ask whether if the College of Physicians in 1849 had officially endorsed what we now accept as the right theory, Snow's theory, many lives would have been saved. I think the answer must be "No."

There is a sentence in Baly's report which was only too true.

"Quarantine can no longer be adopted as the means of preventing the entrance of Cholera into England ; for it is incompatible with the present state of commercial intercourse, and with the well-being of a commercial country."

Perhaps quarantine would not have kept cholera out, but time was to show that something more than fear of epidemics was needed to persuade the electorate to clean up the country. 